\title{
Práticas educacionais nas empresas e o significado do aprendizado para os trabalhadores*
}

\author{
Leonardo Nelmi Trevisan ${ }^{l}$ \\ Pontífice Universidade Católica de São Paulo \\ Elza Fátima Rosa Veloso ${ }^{2}$ \\ Universidade de São Paulo
}

Wilson Aparecido Costa de Amorim ${ }^{3}$ Fundação Instituto de Administração

O objetivo deste estudo é propor agenda de discussões sobre a relação entre educação e trabalho. Foi utilizada pesquisa de âmbito nacional, na qual, anualmente, são levantadas práticas de gestão de pessoas de cerca de 500 empresas, avaliando-se também a percepção de mais de $120 \mathrm{mil}$ profissionais, amostrados por meio do envio, pelas empresas, de relação numerada de seus funcionários em ordem alfabética. Os resultados foram avaliados por meio da análise exploratória de dados e apresentados de forma descritiva; tal avaliação enfatizou tanto a evolução da importância atribuída pelos trabalhadores ao aprendizado e desenvolvimento, quanto a adoção de práticas de treinamento e educação corporativa. Entre os resultados destaca-se que a maior parcela dos trabalhadores indicou que um excelente lugar para trabalhar é "onde percebem que aprendem cada vez mais".
This study aims at proposing a discussion agenda on the relation between education and labor. A research was conducted on a national basis in which, annually, personnel management practices are inventoried on 500 companies, bearing too the perception of over 120 thousand workers, organized by the numbered and alphabetical listing of employees sent by the aforementioned companies. The results were evaluated by an exploratory analysis of data and present descriptively; this evaluation emphasized both the evolution of the attributed importance by the workers regarding learning and development and the adoption of corporate training and learning policies. Among the results it was noted that the majority of the workers identified the best working environment as "where they feel they learn more". It was noted that

\footnotetext{
* Educational practices of companies and the meaning of learning to workers

${ }^{1}$ Membro da Pontífice Universidade Católica de São Paulo.

${ }^{2}$ Membro da Faculdade de Economia, Administração e Contabilidade da Universidade de São Paulo. Endereço para correspondências: Rua Cayowaá 1366, Apto 103, Perdizes, São Paulo, SP, 05918-001 (elzafr@usp.br)

${ }^{3}$ Membro da Fundação Instituto de Administração.
} 
Notou-se que as empresas recebem mão de obra com percepção da eficiência da educação já constituída.

Palavras chave: Educação - Trabalho Aprendizagem - Educação corporativa the companies receive workers with the perception of education efficiency already constituted.

Keywords: Education - Labor - Learning - Corporate education

\section{Introdução}

A

exigência das empresas por escolaridade dos trabalhadores acompanha um quadro social pré-définido. Neste quadro, a oferta de educação na sociedade brasileira vem crescendo gradativamente, bastando observar o crescimento da proporção de trabalhadores brasileiros com nível educacional médio, que em 1995 representavam 18,3\% dos empregados formais e em 2000 , em 2005 e 2007 passaram para $24,6 \% ; 33,4 \%$ e $36,8 \%$, respectivamente (MINISTÉRIO DO TRABALHO E EMPREGO, 2008).

Dessa forma, é possível supor que os trabalhadores percebem a importância do aprendizado e desenvolvimento nos ambientes corporativos não só por que as empresas agem de maneira afirmativa nesse sentido. Mas também por que os indicadores educacionais nacionais têm apresentado variação positiva como o aumento da escolaridade da população e de maior aceitação nos processos de seleção daqueles com maior escolaridade nas empresas. As organizações reagem a uma situação gerada pela oferta educacional de escolaridade crescente, ou seja, a empresa recebe a pressão desse processo e não apenas age sobre ele.

O objetivo deste estudo é propor uma agenda de discussões sobre a relação entre educação e trabalho no Brasil tomando por base a evolução da escolaridade entre os trabalhadores formais brasileiros. Para tanto, foram utilizados dados de uma pesquisa de âmbito nacional, na qual, anualmente, são levantadas as práticas de gestão de pessoas de cerca de 500 empresas, apurando-se também seu clima organizacional por meio da percepção de mais de 120 mil profissionais.

A análise dos dados levantados procurou enfatizar tanto a evolução da importância atribuída pelos trabalhadores ao aprendizado e desenvolvimento quanto o nível de adoção de práticas de treinamento, desenvolvimento e educação corporativa. Para evidenciar a relação entre educação e trabalho, foram utilizados dados quantitativos tratados por meio de análises exploratórias. Este trabalho foi dividido da seguinte forma: após a introdução, são apresentadas a descrição da pesquisa e sua metodologia e os resultados encontrados. No tópico seguinte, tais resultados são discutidos a partir dos seguintes assuntos, que apóiam o raciocínio desenvolvido neste trabalho: economia baseada no conhecimento, 
o papel da educação na economia do conhecimento, as novas exigências da sociedade do conhecimento, a educação no ambiente de trabalho; por último, as considerações finais apresentam apontamentos para o desenvolvimento de uma futura pesquisa.

\section{Descrição da pesquisa e metodologia}

Os dados utilizados se referem a uma amostra de empresas participantes de uma pesquisa realizada anualmente entre 2006 e 2008 , com companhias que procuram se destacar em termos de clima organizacional e práticas de gestão de pessoas. Obteve-se uma amostra anual, já mencionada, de mais de $120 \mathrm{mil}$ empregados de cerca de 500 empresas atuantes no mercado brasileiro e/ou internacional por mais de cinco anos. Essas empresas têm em comum a pretensão de se destacar por seu clima organizacional positivo e por suas práticas diferenciadas de gestão de pessoas. Porém, tais empresas apresentam características que as distinguem umas das outras: porte, setor ou região de atuação no país, origem do capital, entre outros.

Para a realização do procedimento amostral, foi solicitado às empresas que enviassem uma relação numerada de seus funcionários em ordem alfabética e, a partir dela, foram sorteados os que deveriam responder à pesquisa (através de números correspondentes aos atribuídos para os funcionários listados). Todos os sorteados eram empregados com vínculo formal de trabalho. Não puderam participar estagiários ou terceiros que não trabalhassem exclusiva e permanentemente na empresa. A quantidade de questionários enviados a cada organização participante obedeceu aos seguintes critérios:

- Se o número de funcionários da empresa era menor ou igual a 200 , então tamanho para amostragem foi igual a 200 ;

- Se o número de funcionários da empresa era menor ou igual a 500, então tamanho para amostragem foi igual a 300 ;

- Se o número de funcionários da empresa era menor ou igual a 1500 , então tamanho para amostragem foi igual a 400 ;

- Se o número de funcionários da empresa era menor ou igual a 2500 , então tamanho para amostragem foi igual a 500 ;

- Se o número de funcionários da empresa era menor ou igual a 5000, então tamanho para amostragem foi igual a 600 ;

- Para qualquer outro caso, tamanho para amostragem foi igual a 900.

O procedimento descrito acima foi elaborado visando a obter representatividade em cada organização participante. Para mensurar o clima organizacional, 
foi aplicado um questionário com 64 questões, respondidas por meio de escala Likert. Foi também elaborada a seguinte questão geral: $O$ que faz você considerar uma empresa um excelente lugar para se trabalhar? Tal questão figurava no questionário antes das 64 questões e aceitava somente uma opção de resposta. Neste trabalho foram utilizadas somente as respostas à questão geral ilustrada no Quadro 1, que era aplicável a qualquer organização, e não somente à organização onde o respondente trabalhava. Cada uma dessas alternativas de resposta se relacionava a uma das categorias de pesquisa, nomeadas da seguinte forma: Identidade, Satisfação e Motivação; Aprendizado e Desenvolvimento, e Liderança. Neste trabalho, a alternativa analisada referese à categoria Aprendizado e Desenvolvimento.

\section{Quadro 1}

Questão geral e alternativas de resposta

\section{O que faz você considerar uma empresa um excelente lugar para se trabalhar?}

\begin{tabular}{|l|c|}
\hline $\begin{array}{l}\text { Eu compreender e concordar com os objetivos da empresa, } \\
\text { com aquilo que ela faz para seus clientes, para a sociedade e } \\
\text { para a comunidade. }\end{array}$ & Identidade \\
\hline $\begin{array}{l}\text { Eu me sentir satisfeito(a) e motivado(a) com aquilo que faço, } \\
\text { com o que ganho e com o dia-a-dia de trabalho. }\end{array}$ & $\begin{array}{c}\text { Satisfação e } \\
\text { motivação }\end{array}$ \\
\hline $\begin{array}{l}\text { Eu perceber que estou aprendendo cada vez mais e que tenho } \\
\text { oportunidade de crescer como profissional e como pessoa. }\end{array}$ & $\begin{array}{c}\text { Aprendizado e } \\
\text { desenvolvimento }\end{array}$ \\
\hline $\begin{array}{l}\text { Ter chefes que eu respeite, confie e que orientem } \\
\text { adequadamente sua equipe de trabalho. }\end{array}$ & Liderança \\
\hline Nenhum dos motivos descritos acima. & NS/NR \\
\hline
\end{tabular}

Adicionalmente, cada uma das empresas respondeu a um questionário sobre suas políticas e práticas de Gestão de Pessoas, que obedeceu ao critério de múltipla escolha, onde as práticas aqui analisadas estavam inseridas (ALMEIDA \& BOTELHO, 2006).

Os resultados foram avaliados por meio da análise exploratória de dados, que é uma técnica usualmente utilizada para "organizar dados e apresentá-los de forma a perceber as informações subjacentes, elucidando o trabalho de pesquisa" (CAZORLA, 2001; p. 21). Portanto, os dados foram apresentados de forma descritiva. Essa técnica da análise foi aplicada para a obtenção de proporções de interesse, que subsidiassem as análises pretendidas. Tais proporções foram convertidas em percentuais e apresentadas em gráficos de barras e tabelas. 


\section{Resultados}

As questões investigadas relacionavam-se às práticas de gestão de pessoas em empresas que pretendem se destacar no ambiente empresarial como melhores lugares para se trabalhar. $\mathrm{O}$ foco específico recaiu sobre as práticas de treinamento, desenvolvimento e educação corporativa segundo a percepção de seus empregados. O pressuposto adotado quando da formulação das questões foi de que a visão de um excelente lugar para se trabalhar vincula-se à Educação. Desta forma, um excelente lugar para se trabalhar é onde os trabalhadores percebem que estão aprendendo cada vez mais e que têm oportunidade de crescer como profissionais e como pessoas. Na Tabela 1, é apresentada a evolução da visão dos empregados sobre o que consideram como um excelente lugar para se trabalhar.

\section{Tabela 1}

O que faz você considerar uma empresa um excelente lugar para se trabalhar?

\begin{tabular}{lccc}
\hline Categorias de Resposta & $\mathbf{2 0 0 6}$ & $\mathbf{2 0 0 7}$ & $\mathbf{2 0 0 8}$ \\
\hline Identidade & 20,8 & 24,0 & 24,1 \\
Satisfação e motivação & 37,6 & 25,0 & 25,2 \\
Aprendizado e desenvolvimento & $\mathbf{3 6 , 0}$ & $\mathbf{3 9 , 8}$ & $\mathbf{4 0 , 3}$ \\
Liderança & 4,6 & 6,0 & 5,9 \\
NS/NR & 1,1 & 4,4 & 4,4 \\
\hline
\end{tabular}

As categorias apresentadas na Tabela 1, também mencionadas no Quadro 1, nortearam a elaboração do questionário aplicado aos empregados das empresas inscritas, assim como a análise dos resultados obtidos. Na categoria "identidade" estão agrupados os dados referentes ao nível de integração das pessoas à empresa e à sua estratégia, considerando o quanto os empregados acreditam que a empresa corresponde aos seus valores pessoais e à sua forma de pensar e agir; na categoria "satisfação e motivação" estão agrupadas as opiniões das pessoas sobre as experiências que vivem na empresa e o que recebem pelo seu trabalho, também pela propensão de realizar mais do que realizam naquela organização; a categoria "aprendizado e desenvolvimento" é definida pelo tanto que as pessoas se sentem em crescimento intelectual, pessoal e profissional na organização na qual trabalham; a categoria "liderança" representa o grau de credibilidade e confiança nas chefias. A sigla NS/NR significa "não sei/não desejo responder". 
Conforme Tabela 1, os resultados apontam que, em 2008, a categoria "Aprendizado e Desenvolvimento" foi a resposta mais freqüente dos trabalhadores das empresas pesquisadas, com $40,3 \%$ das respostas, ou seja, na visão dos participantes, um excelente lugar para se trabalhar vincula-se ao quanto os empregados sentem que estão aprendendo e se desenvolvendo. Em segundo lugar, observa-se que esta proporção cresceu ao longo dos três anos pesquisados, já que em 2006 esta categoria correspondia a 36,0\% das respostas. Um terceiro aspecto é que nenhuma das demais categorias adquiriu proporção próxima à verificada para "Aprendizado e Desenvolvimento". Desta forma, a maior parcela dos trabalhadores indicou que um excelente lugar para se trabalhar é onde percebem que estão aprendendo cada vez mais e que têm oportunidade de crescer como profissionais e pessoas, deixando em segundo plano as categorias "Identidade", "Satisfação e motivação" e "Liderança".

A percepção mais acentuada dos trabalhadores sobre a importância do aprendizado e desenvolvimento nas empresas, como características de um excelente lugar para se trabalhar, encontra uma contrapartida nas práticas adotadas pelas empresas em que trabalham, conforme Figura 1.

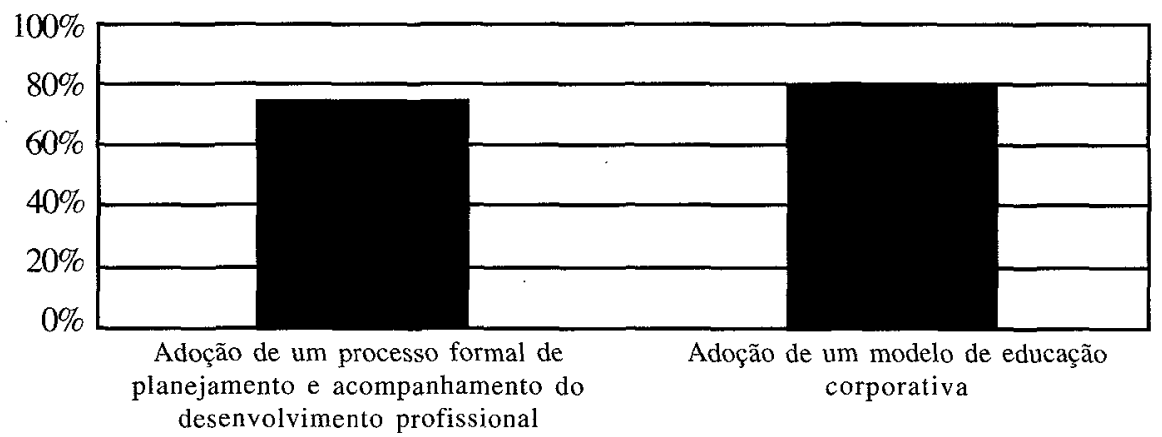

Figura 1

Adoção de práticas relacionadas à educação e qualificação dos empregados

A metodologia da pesquisa, além da apuração da percepção dos empregados sobre vários aspectos do ambiente organizacional, previa a apuração das práticas de gestão de pessoas adotadas pelas empresas participantes. A Figura 1 demonstra que, do conjunto dessas empresas, 76,0\% declararam ter um processo formal de planejamento e acompanhamento do desenvolvimento profissional de seus empregados. Da mesma maneira, 80,0\% destas empresas também afirmaram adotar um modelo de educação corporativa.

Os dados apresentados demonstram que desenvolvimento profissional, no sentido que vem sendo assumido pela expressão "educação corporativa" são elementos presentes nas vidas das organizações que pretendem se destacar pela excelência de seu local de trabalho. 
A questão que se coloca é se esta valorização da educação no ambiente corporativo é um fenômeno isolado e típico deste grupo de empresas. A empresa é a única determinante no aumento da percepção de importância do aprendizado e desenvolvimento para a definição de um excelente lugar para trabathar? Ou há variáveis externas do ambiente socioeconômico que desempenham papel preponderante na consolidação desta percepção?

A resposta a esta questão exige identificar, ou perceber, se esta valorização não é decisão endógena ao mundo corporativo, premido pela necessidade de inovar para competir. Dito de outra forma, trata-se também de verificar se, na verdade, não é o ambiente econômico e social que abriga um grande reposicionamento da educação como diferencial competitivo na disputa pelo mercado de trabalho.

O que se sabe é que nos países mais avançados, bem como nos demais, a busca por educação passou a cumprir papel de sustentação dos principais elementos de construção da chamada sociedade do conhecimento. Independentemente das pressões por conhecimento, ampliou-se a procura por maior intensidade de realização educacional. Sem esquecer que a universalização do ensino fundamental alcançada pelo País desde meados dos anos noventa provocou uma ansiedade por continuidade educacional como meio de ascensão profissional.

\section{Discussão}

Economia baseada no conhecimento: uma nova configuração na sociedade contemporânea

Educação e conhecimento são termos inseparáveis, inter-relacionados e interdependentes. Atualmente, o conhecimento é disseminado e produzido mais rapidamente do que antes, adquirindo assim uma nova dimensão. $O$ desenvolvimento de áreas como as tecnologias de informação e comunicação, biotecnologia, engenharia de novos materiais, assume papel-chave neste processo (DAHLMAN, 2002; CASTELLS, 1999) caracterizado como economia baseada no conhecimento (OECD, 1996).

Tal realidade fomentou o debate sobre o conhecimento e suas diversas implicações/aplicações na economia e nas organizações, bem como a discussão sobre a relevância da educação nas sociedades. Esta urgência de investimentos em conhecimento nas EBCs tem pressionado significativamente os sistemas educacionais em todos os níveis, posto que eleva a demanda por educação contínua para todos.

Estas mudanças estão refletidas nos trabalhos dos economistas neo-schumpeterianos. Para eles, a sofisticação da divisão do trabalho e a importância crescente da ciência apontam para uma articulação mais complexa do trabalho, 
identificável em um sistema nacional de inovação. Dentro destes sistemas, a estrutura educacional para manutenção dos fluxos de informação é um prérequisito. Ou seja, os sistemas de inovação institucionalizam a aplicação sistemática da ciência à produção (PAULA et al., 2000).

Fritz Machlup (apud LENHARI \& QUADROS, 2002) - principal precursor do conceito de Economia Baseada no Conhecimento - EBC - destaca que produção e distribuição de conhecimento passaram a ser atividade tanto econômica quanto educacional. Dahlman (2002; p.174) aponta a definição de uma EBC como "aquela que estimula suas organizações e pessoas a adquirirem, criarem, disseminarem e usarem o conhecimento de modo mais eficientemente para um maior desenvolvimento econômico e social". De acordo com Foray e Lundvall (1996), as características importantes desta economia residem na dinâmica estabelecida entre conhecimento tácito e decodificado, na crescente importância das redes de conhecimento e, na aceleração dos processos de aprendizagem interativa. Para Lenhari e Quadros (2002), a EBC assume o conhecimento como principal recurso e a capacidade de aprender como o principal processo em um contexto de rápidas mudanças tecnológicas, de mercado, de formatos organizacionais e da capacidade inovativa como condição de competitividade. Os autores destacam que a aquisição de novas habilidades e conhecimento (learn-to-learn), se traduz na capacidade de aprender e de transformar o aprendizado em fator competitivo e é fundamental neste processo. Por isso, alguns autores como Foray e Lundvall (1996) assumem a EBC como Economia Baseada no Aprendizado. Desta forma, no cerne da economia do conhecimento estão o volume, a natureza e a direção da produção do conhecimento, sua disseminação e seu uso (BENGTSSON, 2002).

- No âmbito macro, a necessidade de maciços investimentos no setor educacional para atingir padrões de competitividade no mercado global tem ampliado a discussão do papel organizador do Estado, para incentivar e estimular o desenvolvimento deste setor ao crescimento econômico e desenvolvimento nacional (TAKAHASHI \& CASTOR, 2000). No âmbito micro, as organizações têm experimentado novos padrões de competitividade neste cenário de redes dinâmicas que exigem novos estilos de gerenciamento (DAHLMAN, 2002). As empresas que desenvolvem vantagens competitivas baseadas no conhecimento mantêm mais facilmente a liderança frente aos seus concorrentes (QUINN et al., 2000).

As demandas da sociedade (macro) e as demandas das organizações (micro) salientam a necessidade de investimentos em educação nas EBCs como forma de atender a demanda por educação contínua para todos. Com isso, a educação e a aprendizagem assumem um papel relevante, levando ao questionamento sobre o seu papel e sua função neste novo contexto (BENGTSSON, 2002). 
Lenhari e Quadros (2002) salientam que conhecer a base de recursos de um país por meio da sua força de trabalho ocupada pode ser um bom indicador para conhecer sua posição na EBC. Desta forma, observa-se o papel fundamental da educação para a força de trabalho, cujas qualificações são aproveitadas no interior do processo produtivo das EBCs.

O papel da educação na economia do conhecimento: a interface entre conhecimento e educação

No Brasil, os estudos sobre o sistema educacional e a gestão escolar, constituem um campo carente de pesquisas, uma área negligenciada, permeada pelos debates ideológicos conflitantes com os estudos gerenciais (TAKAHASHI, 2001). A competitividade do mercado, que também se estendeu ao setor educacional, associada ao nível de turbulência ambiental, demanda novos estudos para eliminar as carências deste setor. Fleury e Fleury (2004; p. 122) destacam a importância da educação no desenvolvimento econômico de um país. Os autores analisam empresas transnacionais e empresas brasileiras, e salientam que "a atratividade do país seria maior se, além dos incentivos econômico-financeiros, houvesse maiores investimentos educacionais, disponibilizando no mercado pessoas mais qualificadas, melhoria na infra-estrutura e a reforma tributária".

Dahlman (2002) indica que o Brasil necessita desenvolver uma estratégia coerente para aproveitar as oportunidades da economia do conhecimento e minimizar os riscos que ela traz, precisa ainda atentar para os gastos com educação de modo eficiente, que é a base para criar, adquirir, adaptar, disseminar, compartilhar e usar o conhecimento, não somente em cursos acadêmicos e bacharelados, mas também em cursos profissionalizantes voltados para atender as necessidades do mundo da produção e do trabalho (CASTRO, 2002; LENHARI \& QUADROS,2002).

Bengtsson (2002) elenca seis questões indispensáveis na agenda das políticas brasileiras para o ingresso mais ativo na economia do conhecimento: inclusão do jovem no sistema educacional, mudança da cultura educacional baseada nos valores da velha economia, alfabetização dos adultos, incremento das parcerias entre o público e o privado, reforma educacional baseada em aprendizagem constante ao longo da vida e o desenvolvimento de uma cultura de aprendizagem.

Uma pesquisa do Banco Mundial auxilia a contextualização do Brasil na EBC ao avaliar a posição de alguns países na economia do conhecimento com base em quatro pilares (que consolidam 70 indicadores estruturais e qualitativos) regime de incentivos econômicos, inovação, infra-estrutura de informação, e educação. 
A pesquisa mostrou que, a partir de 1995, o Brasil melhorou na infra-estrutura de informação e nos incentivos econômicos. Em inovação, apesar de algumas áreas de significativa força tecnológica, seu desempenho foi fraco: houve uma melhora na produção científica, mas não houve melhora quanto ao uso do conhecimento global, medido pela variável de comércio. Em educação, o Brasil apresentou melhora nas matrículas secundárias, mas não em letramento ou educação terciária.

Para Dahlman (2002), a educação é o 'calcanhar de Aquiles' para que o Brasil esteja pronto para a economia do conhecimento, pois uma baixa taxa de educação profíssional e superior implica baixo percentual de trabalhos técnicos e profissionais. Algumas estatísticas evidenciam as condições do sistema educacional brasileiro. Em 2000, o período médio de escolarização era de apenas 4,9 anos no Brasil, enquanto era de 8,8 na Argentina, 7,5 no Chile, 9,4 na Irlanda, 10,0 na Finlândia e 10,8 na Coréia do Sul (países de significativo crescimento econômico nos últimos anos). Considerando a população de 18 a 24 anos no Brasil, o número de matrículas no ensino superior corresponde a apenas $15 \%$ e no ensino médio não ultrapassa 33\% (CASTRO, 2002). Em 1999 apenas 6,7\% do total de ocupados no Brasil possuíam curso superior completo. Entre 1989 e 1999, no setor industrial, a participação do número de ocupados com curso superior aumentou apenas de $3,9 \%$ para $5,2 \%$, enquanto, por outro lado, a indústria eliminou $48,1 \%$ dos trabalhadores com escolaridade até o ensino fundamental.

As novas exigências da sociedade do conhecimento - a expansão do ensino universitário

O Brasil, como as demais economias industrializadas, iniciou desde os anos de 1970 uma forte expansão do ensino superior. Estudo da Organização para a Cooperação e Desenvolvimento Econômico (OCDE, 2008) mostrou que, embora expansão tenha ocorrido em todos os países com economias avançadas, a taxa dessa expansão variou muito nesses países. Entre os 30 países com economias industrializadas que integram a OCDE, três deles foram os que alcançaram períodos de mais rápida expansão: Coréia do Sul, Irlanda e Espanha. Nesses casos, mesmo partindo de níveis muito baixos, os três duplicaram a proporção de graduados no ensino superior que entraram na força de trabalho entre o último ano da década de 1970 até o final da década de 1990. A razão dessa expansão era bem conhecida: necessidade de habilidades mais qualificadas para atender a demanda por mão de obra mais adaptada à uma sociedade de conhecimento.

$O$ efeito que esse aumento de oferta de mão de obra com formação de ensino superior alcançou no mercado de trabalho também variou entre os países industrializados. A hipótese desenvolvida no estudo da OCDE é de que a 
grande oferta de qualificados com formação universitária fez com que parte desses novos graduados fosse obrigada a trabalhar em empregos que não exigiam os níveis de formação atingidos com a conclusão do ensino superior. $O$ estudo da entidade internacional também considerou a hipótese de que esses trabalhadores com formação universitária, ao disputarem postos de trabalho com candidatos de formação inferior, gerassem um efeito excludente, agravando as taxas de desemprego dos níveis mais baixos de qualificação (OCDE, 2008).

Avaliar o impacto da maior oferta de mão de obra mais qualificada gerou a constituição de indicadores educacionais específicos para economias industrializadas. O primeiro aspecto desse indicador mediu o estágio inicial da formação de mão de mão de obra para a sociedade do conhecimento: a conclusão do ensino médio. O estudo da OCDE mostrou que, nas economias industrializadas mais avançadas, o que inclui o Brasil, há uma compensação no mercado de trabalho por alcançar o ensino médio e uma punição por não fazê-lo. As taxas de retorno financeiro da realização educacional são muito mais altas nos investimentos realizados na sequiência direta da educação fundamental do que em um eventual retorno no meio da carreira (por exemplo, na faixa dos 40 anos) para o sistema educacional. A partir dessa constatação, o estudo da OCDE analisou as faixas etárias presentes no mercado de trabalho das economias mais industrializadas com ensino médio concluído.

A parcela da população que concluiu o ensino médio aumentou em todos os países da OCDE: em 2005, entre 22 países da organização, a proporção de pessoas entre 25 e 34 anos empregadas que concluíram o ensino médio variava entre o mínimo de $73 \%$ e o máximo de $94 \%$. Quando se inclui, além desses 22 países, as economias parceiras da Eslovênia, Estônia, Federação Russa e Israel, o estudo da OCDE mostrou que o índice de concluintes do ensino médio na mesma faixa etária recua para $60 \%$ em média. Porém, quando a esse cálculo integram-se as economias de Espanha, México, e Turquia, o índice médio de população empregada com ensino médio recua para $50 \%$, na mesma faixa etária entre 25 e 34 anos. Observe-se, no entanto, o aspecto mais relevante dessa comparação internacional: no conjunto dos países da OCDE, a proporção de indivíduos na faixa entre 25 e 34 anos que atingiram o ensino médio e estão empregados é 13 pontos percentuais mais alto do que a proporção dos que compõem o grupo entre 45 e 54 anos de idade. Em alguns países essa diferença é bem mais acentuada e indica o investimento na realização educacional nas últimas duas décadas. É o caso de Coréia do Sul, Espanha, Grécia, Turquia e na economia parceira do Chile. É essencial observar que na Alemanha e nos Estados Unidos, a proporção de indivíduos que alcançaram o ensino médio é praticamente o mesmo entre os três grupos de faixas etárias: entre 25 e 34 anos, entre 35 e 44 anos e entre 45 e 54 anos (OCDE, 2008). 
O impacto dessa realização educacional sobre os níveis educacionais foi de igual intensidade. Há compensações significativas associadas à aquisição de padrões educacionais melhores, especialmente no ensino superior e penalidades igualmente relevantes associadas à não conclusão de pelo menos o ensino médio. Em todos os países da OCDE, os ganhos salariais associados ao ensino superior em comparação ao ensino médio ficam acima de $25 \%$ e em alguns países (Turquia e México, por exemplo) superam os $100 \%$. As taxas médias de desemprego revelam, nos países da OCDE, como ocorre a penalidade pela não aquisição de educação média; a não conclusão do ensino médio sinaliza taxas de desemprego 12 pontos percentuais maiores para a mesma faixa etária em relação aos que concluíram essa etapa de realização educacional. Merece atenção, no entanto, que a acentuada oferta de ensino superior não necessariamente reduz as taxas de desemprego dependendo da economia das novas sociedades do conhecimento. Entre 1995 e 2004, a Finlândia não teve expansão do ensino superior e registrou queda do desemprego, enquanto a Polônia ampliou intensamente a educação superior e registrou significativa expansão das taxas de desemprego nesse período. Já Coréia do Sul e Irlanda registraram forte crescimento na oferta de educação superior com queda na taxa de desemprego, na mesma comparação cronológica.

O ponto central dessa realização educacional é a expansão do ensino médio. Tomando como referência o ano de 2005 o estudo da OCDE mostrou que no Brasil, na população empregada, na faixa entre 25 e 34 anos, $38 \%$ concluiu o ensino médio, índice que caia para $32 \%$ na faixa entre 35 e 44 anos, recuando para $27 \%$ na faixa entre 45 e 54 anos e acentuando a queda para $11 \%$ na faixa entre 55 e 64 anos. Esses números são bastante diferenciados das economias emergentes diretamente concorrentes do Brasil, caso da Coréia do Sul que atingiu $97 \%$ de sua população ocupada na faixa entre 25 e 34 anos com ensino médio concluído em 2005 , recuando para $88 \%$ na faixa seguinte entre 35 e 44 anos para $60 \%$ na faixa entre 45 e 54 e atingindo a média de $35 \%$ de formados no ensino médio na faixa entre 55 e 64 anos.

A comparação dos resultados de realização educacional do Brasil no contexto latino-americano é complexa e comporta forte variação. Por exemplo, como mostrou o estudo da OCDE, no caso do México, apenas $24 \%$ da população empregada na faixa entre 25 e 34 anos concluiu o ensino médio (resultado bem inferior ao obtido pelo Brasil), índice que recua para $23 \%$ na faixa etária seguinte entre 35 e 44 anos, volta a cair para $20 \%$ na faixa etária entre 45 e 54 anos (posições sempre inferiores às alcançadas pelo Brasil) e cai fortemente para $12 \%$ de concluintes do ensino médio empregados na faixa entre 55 e 64 anos (o único resultado que supera o Brasil). No entanto, quando a comparação do caso brasileiro é feita com o Chile os resultados são bem diferenciados: na faixa etária entre 25 e 34 anos, $64 \%$ dos empregados concluíram o ensino médio, 
praticamente o dobro do Brasil, fato que se repete na faixa seguinte, entre $35 \mathrm{e}$ 44 anos quando o índice de concluintes atinge 52\% de empregados com ensino médio completo e segue bem maior na faixa entre 45 e 54 anos, com $44 \%$ de empregados com esse nível de escolaridade. Curiosamente, na faixa etária entre 55 e 64 anos, o Chile tem praticamente três vezes mais concluintes de ensino médio empregados do que o Brasil, alcançando $32 \%$ nessa faixa etária.

Observe-se que o atendimento da exigência de ensino médio completo em toda a população empregada, nas diferentes faixas etárias é importante sinal de equilíbrio na oferta de trabalho na sociedade do conhecimento, por exemplo, os Estados Unidos, têm $87 \%$ de sua população empregada na faixa entre 25 e 34 anos com ensino médio completo e repete o índice, com 86\% desse nível de escolaridade nos empregados na faixa etária entre 55 e 64 anos, praticamente o mesmo índice alcançado nas faixas etárias intermediárias. $\mathrm{Na}$ Alemanha, o quadro é igual: na faixa etária entre 25 e 34 anos $84 \%$ da mão de obra empregada tem ensino médio completo, enquanto na faixa etária entre 55 e 64 anos, 79\% está nessa condição de escolaridade.

A situação de realização educacional brasileira fica mais distante das sociedades de conhecimento mais avançadas no caso da educação superior. $\mathrm{O}$ estudo da OCDE referente ao ano de 2005 mostrou que apenas $8 \%$ da população empregada na faixa entre 25 e 34 anos têm nível superior completo, subindo para $9 \%$ na faixa entre 35 e 44 anos, o mesmo índice da faixa seguinte, entre 45 e 54 anos, caindo vertiginosamente para apenas $4 \%$ na faixa etária entre 55 e 64 anos. O maior problema está na comparação com nossos concorrentes diretos: na Espanha, na faixa etária entre 25 e 34 anos $40 \%$ da população empregada tem nível superior completo, enquanto na Coréia do Sul, nessa mesma faixa etária, $51 \%$ da força de trabalho tem a universidade concluída, ou seja, cinco e 6,3 vezes mais, respectivamente, do que o Brasil. Essa diferença recua na faixa etária entre 55 e 64 anos porque a Espanha tem 10\% de seus empregados com ensino superior completo e a Coréia do Sul tem 14\% nessa condição, portanto 2,5 e 3,5 vezes, respectivamente, mais que o Brasil.

$\mathrm{Na}$ comparação com os vizinhos latino-americanos a situação brasileira de realização educacional de nível superior permanece difícil. Na faixa etária entre 25 e 34 anos o México tem $15 \%$ de seus empregados com universidade concluída enquanto o Chile, nessa mesma faixa etária tem $13 \%$ nessa condição educacional, praticamente o dobro do Brasil. Já na faixa etária entre 55 e 64 anos, o México tem $8 \%$ da população empregada com universidade concluída, e o Chile $9 \%$, superando em mais do que o dobro a realização educacional brasileira na mão d e obra com padrão universitário.

A observação desse quadro de comparação internacional não suporta, no entanto, exacerbada crítica sobre o processo de realização educacional da mão de obra brasileira. $O$ trabalhador brasileiro fez um contínuo investimento em 
educação formal, atendendo a oferta do poder público de cobertura quase universal da oferta de educação fundamental operacionalizada desde o início da década de 1990 (SOUZA, 2005). As gerações que desde esse momento completaram os oito anos obrigatórios de ensino fundamental pressionaram a demanda por ensino médio, tanto o de perfil profissional como o de etapa necessária para a educação de nível universitário. A observação da tabela construída a partir dos dados oferecidos pela RAIS (Relação Anual de Informações Sociais) confirma de modo consistente essa evolução induzida da realização educacional de ensino básico da mão de obra brasileira. Mesmo sem o estabelecimento de uma divisão por faixa etária é possível observar nessa tabela que o grau de escolaridade média do trabalhador formal brasileiro, em termos percentuais, dobrou entre 1995 e 2007.

É preciso acompanhar com cautela essa evolução porque ela alcançou impactos bem diferenciados quanto a números absolutos. Em 1995, 18,33\% dos trabalhadores formais tinham ensino médio completo o que significava cerca de 4,3 milhões de pessoas. Em 2000, essa porcentagem atingia $24,63 \%$ dessa massa trabalhadora formal, embora o número dos trabalhadores com ensino médio concluído já representasse 6,4 milhões de pessoas. Com a economia estável e os investimentos crescentes, em 2005, pela tabela mencionada, $33,44 \%$ dos trabalhadores formais tinham escolaridade média, o que já significou um total de 11,1 milhões de pessoas. Em 2007, esse nível educacional atingiu $36,84 \%$ dos trabalhadores formais, o que representou um total de 13,8 milhões de pessoas com ensino médio concluído na mão de obra formal do País. Ou seja, acompanhando o mesmo critério comparativo entre 1995 e 2007 o Brasil multiplicou por 3,4 vezes a realização educacional de nível médio. Nesse aspecto não é um índice muito diferente do obtido pela Espanha ou pela Coréia do Sul.

É fato que no que diz respeito a realização educacional de nível universitário o salto foi bem menor. Em 1995, uma parcela de $11,1 \%$ da massa trabalhadora formal tinha educação universitária completa o que representava 2,6 milhões de pessoas no Brasil; em 2007, essa porcentagem alcançou 15,2\%, o que significou 5,7 milhões de trabalhadores com nível superior completo de escolaridade. Na mesma comparação, essa realização educacional apenas dobrou nesse período.

\section{A educação no ambiente de trabalho}

A proposta de relação entre oferta educacional pela empresa e seus objetivos estratégicos foi formulada por Meister (1999) que enumerou as forças que impulsionam essa vinculação. Essas forças incluem a demanda por flexibilidade 
operacional nas empresas (tanto por parte da estrutura organizacional como dos trabalhadores), a pressão da era do conhecimento, com todas as suas imposições de obsolescência dos ciclos tecnológicos e uma nova exigência de constante empregabilidade por parte da mão de obra (com o fim da vitaliciedade do conceito de emprego). Todos esses fatores confluiram para novas funções do processo educacional, entendido como uma ação estratégica essencial para a empresa manter ou conquistar mercados.

Nesse quadro, a empresa se transformou em um ambiente em constante demanda por aprendizagem. Desde o início dos anos 1990, as condições para essa aprendizagem organizacional foram exploradas por diferentes autores, Garvin (1993) enfocou a sistematização de atividades que promove a prática da aprendizagem nas organizações. Garvin propôs uma sequiência de atividades na empresa, não hierarquizadas, que vão desde o constante ímpeto pela solução de problemas passando pela repetida experimentação, aproveitamento de experiências passadas além de forte incentivo à circulação de conhecimento.

O processo de aprendizagem na organização também foi analisado por Kim (1993) a partir de essencial distinção entre aprendizado operacional, referente à assimilação de habilidades inerentes às funções operacionais do trabalhador, e o aprendizado conceitual, quando o funcionário desenvolve o poder de articular conhecimentos básicos, conceituais, sobre uma determinada atividade ou experiência. Para esse autor, todo o processo de incentivo à aprendizagem nas organizações buscou uma fusão entre essas duas formas de aprendizagem, a operacional, mais próxima do saber fazer, e a conceitual, mais vinculada ao modo de pensar uma atividade.

Há, também, nessa interação entre oferta educacional e objetivos estratégicos, a dupla tarefa de, primeiro, diminuir a obsolescência do conhecimento com um processo em que a aprendizagem agrega valor de modo contínuo à disputa por mercado da empresa e, depois, do trabalhador usar esse esforço necessário da empresa para assimilar conhecimento novo e preservar sua qualificação também de modo contínuo. Nesse aspecto, ganha importância voltar à perspectiva de Meister (1999), para quem a busca de vantagem competitiva constrói aprendizado permanente e um desempenho excepcional. Nesse processo, para essa autora, aprendizagem na corporação indica valor adicional, remuneração intangível que o trabalhador procura e reconhece. Merece atenção, portanto, o estudo da Hewit Associates (2004; apud GDKIAN et al., 2009), sobre os melhores empregadores identificando as cinco características básicas que essas empresas devem possuir. Todas estas características vinculam-se, direta ou indiretamente, à capacitação no trabalho: a primeira relaciona-se à inspiração de liderança, quando o lugar do líder é bem visível para toda a empresa e estes estão especialmente envolvidos no desenvolvimento dos talentos; 
a segunda, refere-se à cultura de empresa única, voltada à adequação à cultura organizacional; a terceira, baseada no foco no crescimento do talento, no investimento de recursos no desenvolvimento dos empregados, com gestores responsáveis por esse desenvolvimento; a quarta, refere-se ao impulso por um forte senso de resultado, quando as revisões regulares de rendimento são usadas para definir o que a empresa espera do empregado e a expectativa deles em relação à empresa; e, por último, quando as práticas de Recursos Humanos estão alinhadas à excelência da execução, a empresa passa a valorizar explicitamente a experiência das pessoas como relevante para suas estratégias de negócios.

Esse raciocínio em torno da relação entre oferta educacional e objetivo estratégico ajuda a compreender a escala de avaliação das empresas consideradas nesta pesquisa, construída sobre a idéia de qualificação como valor agregado à remuneração contratual. $\mathrm{Na}$ sociedade do conhecimento, a empresa se transformou em lócus especial dessa procura.

\section{Considerações finais}

\section{Apontamentos para o desenvolvimento de uma futura pesquisa}

A pesquisa apresentada no início deste artigo trouxe como resultado a evolução da importância atribuída ao aprendizado no trabalho, concomitantemente ao avanço das organizações em adotar algum tipo de ação voltada ao desenvolvimento dos empregados. Boa parte das empresas está criando um sistema de aprendizagem contínua, além de compreender a importância da educação vinculada às metas pessoais dos empregados e empresariais.

Por outro lado, há dados que confirmam que a massa trabalhadora brasileira fez um enorme esforço de realização educacional de caráter rigorosamente formal, atendendo a oferta essencial do ensino público. Essa massa trabalhadora, com essa qualificação formal, chegou ao mercado profissional capaz de identificar as melhores oportunidades nas empresas com ofertas mais consistentes de capacitação, com todos os recursos cognitivos para identificar essas ofertas.

Desta maneira, quanto mais a empresa recebe trabalhadores com maior escolaridade, mais eles identificam na aprendizagem um fator qualificador dessa empresa. Cabe descobrir, portanto, em que medida as empresas realmente regulam a importância do aprendizado e desenvolvimento em uma sociedade que valoriza crescentemente a educação como sinal de desenvolvimento econômico e social.

Ao fim deste artigo identificou-se como oportuno propor uma agenda de discussões sobre a relação entre educação e trabalho no Brasil tomando por base a evolução da escolaridade entre os trabalhadores formais brasileiros. 
Nesta agenda, uma primeira hipótese refere-se às formas de absorção de mão de obra pelas empresas. Posto que a pesquisa revelou uma crescente valorização pelo trabalhador das ofertas de capacitação das empresas, formulamos, portanto como hipótese que a empresa recebeu uma mão de obra com uma percepção da eficiência da educação já constituída, e não que ela, empresa como instituição a formulou.

Ao longo dos anos a aprendizagem se torna mais relevante ao trabalhador que outros fatores que incluem remuneração, liderança e identidade. Por isto, supõe-se por meio dos resultados da pesquisa que a oportunidade de aprender e se desenvolver é considerada pelo trabalhador um patrimônio pessoal com maior grau de portabilidade. Ou seja, diferente da boa relação com o chefe, da remuneração diferenciada, da sua identificação com a empresa, o trabalhador leva consigo em sua vida pessoal e profissional o que aprendeu e quanto se desenvolveu. Essa percepção, o trabalhador não constrói na empresa, mas chega à empresa com ela, adquirida na conquista da escolaridade plena.

\section{Agradecimentos}

Ao Progep - Programa de Estudos em Gestão de Pessoas da Fundação Instituto de Administração, pela concessão do acesso aos resultados da pesquisa.

\section{Referências bibliográficas}

ALMEIDA, A.R. \& BOTELHO, D. Construção de questionários. In: BOTELHO, D. \& ZOUAIN, D.M. Pesquisa quantitativa em administração. São Paulo: Atlas, 2006.

BENGTSSON, J. Educação para a economia do conhecimento: novos desafios. In: VELLOSO, J.P.R. O Brasil e a economia do conhecimento. Pp. 403-13. Rio de Janeiro: José Olympio, 2002.

CASTELLS, M. A era da informação: economia, sociedade e cultura. A sociedade em rede. Volume 1, pp. 86-221, São Paulo: Paz e Terra, 1999.

CASTRO, M.H.G. Um sistema de educação para atender à economia do conhecimento. In: VELLOSO, J.P.R. O Brasil e a economia do conhecimento. Pp. 391-402. Rio de Janeiro: José Olympio, 2002.

CAZORLA, I.C. Educação estatística: análise exploratória. Cap. III. Ilhéus, 2001. Disponível em: <http://www.socio-estatistica.com.br/Edestatistica/apostila.htm. 
DAHLMAN, C.J. A economia do conhecimento: implicações para o Brasil. In: VELLOSO, J.P.R. O Brasil e a economia do conhecimento. Pp. 161-96. Rio de Janeiro: José Olympio, 2002.

FLEURY, A. \& FLEURY. M.T.L. Aprendizagem e inovação organizacional: as experiências de Japão, Coréia e Brasil. São Paulo, Atlas, 1997.

FLEURY, A.C.C. \& FLEURY, M.T.L. Estratégias empresariais e formação de competências: um quebra cabeça caleidoscópico da indústria brasileira. $2^{\mathrm{a}}$ Edição. São Paulo: Atlas, 2004.

FORAY, D. \& LUNDVALL, B.A. The knowledge-based economy: from the economics of knowledge to the learning economy. In: Employment and Growth in the Knowledge Based Economy. Paris: OECD, 1996.

GARVIN, D. Building a learning organization. Harvard Business Review, Jul-Ago/1993.

GDILIAN, E.A.; SILVA, M.C. \& ÉBOLI, M. Educação corporativa: um estudo exploratório em empresas de destaque. In: FISCHER, A.L.; DUTRA, J.S. \& AMORIM, W.A.C. (Orgs.) Gestão de pessoas: desafios estratégicos das organizações contemporâneas. São Paulo, Atlas, 2009.

GIAMBIAGI, F. Reformas e desequilíbrios macro-econômicos. In: VILELLA, A.; GIAMBIAGI, F.; CASTRO B.C. \& HERMANN, J. Rio de Janeiro: Campus-Elsevier, 2005.

HEWIT ASSOCIATES. What makes a best employer? Insigts and findings from Hewitt's Global Best Employers Study. Disponível em: <was7. hewitt.com/ bestemployers/pdfs/BestEmployer.pdf.

KIM, D.H. The link between individual and organizational learning. Sloan management review, Fall, 1993.

LENHARI, L.C. \& QUADROS, R. Recursos humanos nas economias baseadas no conhecimento. Revista inteligência empresarial,12: 30-8, Julho/2002.

MEISTER, J. Educação corporativa. São Paulo, Makron Books, 1999.

MINISTÉRIO DO TRABALHO E EMPREGO. Características do emprego formal segundo a Relação Anual de Informações Sociais - 2007. Brasília, 2008.

OECD. The knowledge-based economy. Paris: OCDE, 1996.

OCDE. Panorama da educação 2007: indicadores OCDE. São Paulo: Moderna, 2008. 
PAULA, J. A.; CERQUEIRA, H. E. G.; ALBUQUERQUE, E. M. Trabalho e conhecimento: lições de clássicos para a análise do capitalismo contemporâneo. Estudos Econômicos - FIPE USP, 30(3): 419-45, Jul-Set/2000.

QUINN, J.B.; ANDERSON P. \& FINKELSTEIN, S. Gerenciando o intelecto profissional: extraindo o máximo dos melhores. In: Gestão do conhecimento. Coleção Harvard Business Review. Pp. 174-96. Rio de Janeiro: Campus, 2000.

SOUZA, P.R. A evolução gerenciada: educação no Brasil. São Paulo, Pearson Prentice Hall, 2005.

TAKAHASHI, A.R.W. \& CASTOR, B.V.J. Globalização: produção de conhecimento, tecnologia de informação e competitividade internacional - o caso do Brasil. Anais do XXIV Encontro Anual da ANPAD (CD-Rom): Florianópolis, 2000.

TAKAHASHI, A.R.W. Contexto ambiental, esquemas interpretativos e estratégias de ação: estudo comparativo de casos em duas organizações escolares de ensino público de Curitiba/PR. Dissertação de Mestrado, Centro de Pesquisa e Pós-Graduação em Administração, Universidade Federal do Paraná, 2001. 